\title{
THE RELATIONSHIP OF CYSTIC LESIONS OF THE ACINI OF THE PANCREAS TO AGE, CAUSE OF DEATH, AND FIBROCYSTIC DISEASE IN CHILDREN
}

\author{
BY \\ J. L. EMERY \\ From the Children's Hospital, Sheffield, and Department of Pathology, the University of Sheffield
}

(Received for Publication March 3, 1951)

Dilated plugged acini in the pancreas are one of the fundamental histological features in 'fibrocystic disease.' Andersen (1938), however, in her original article on 'Fibrocystic Disease in the Pancreas in Relation to Celiac Syndrome' pointed out that cystic acini occur in a large number of children, and she was careful to confine her diagnosis of fibrocystic disease to cases where more than $90 \%$ of the acini of the gland were affected.

Following Andersen's work there has been an increased interest in the presence of cystic changes in the acini of the pancreas, and lesions have been described in a number of apparently quite different conditions. Baggenstoss (1947, 1948a and b) described a high incidence of plugged acini in chronic nephritis, hypertension, uraemia, ulcerative colitis, and intestinal obstruction; Mallory (1947) in severe infections and in all of 24 cases of typhus; Gillman and Gillman (1945) found the lesion in malnutrition in South Africa; Wallace and Ashworth (1942) and Andrew (1944) in old age; and Hartz (1948) in patients dying after starvation. Relatively little interest appears to have been taken in the significance of these plugged acini in children not showing the full fibrocystic syndrome. An attempt has been macie here to determine the incidence of plugged and cystic acini in the pancreas of children at necropsy, and to relate these lesions to the clinical disease and age of the children.

\section{Material and Methods}

Blocks were taken from the head and tail of the pancreas of children coming to necropsy at the Sheffield Children's Hospital during the years 1947-50. Sections were stained with haemotoxylin and eosin and also with Masson's trichrome. With the latter stain the colloids in dilated acini frequently take on a different colour from that of the surrounding cells, making the plugged acini much more easily identifiable than in a haemotoxylin-eosin preparation. All glands were excluded which showed gross post-mortem autolysis, or had been affected by extensive lesions such as tumour infiltration or haemorrhage. The number of glands remaining and analysed from 400 necropsies was 310 .

The clinical features recorded were the age of the child, duration of illness, cause of death, presence or absence of staphylococcal infection, and the major disease causing death.

The glands were divided into four groups: (1) showing fibrocystic disease in which the majority of acini were affected and corresponding to the lesions described by Andersen (1938); (2) in which plugged acini were readily identified on the sections and were a prominent feature of the pancreas, although affecting less than $90 \%$ of the acini; (3) cases in which plugged acini were found in small numbers affecting less than $1 \%$ of the acini; (4) no lesions.

For this survey a pancreas was reported as negative if plugged acini were not found in at least two complete cross sections taken from different parts of the gland.

\section{Results}

Of the 310 glands examined, fully developed fibrocystic disease was present in $11(3.5 \%)$ cases; large numbers of plugged acini were found in 23 $(7.5 \%)$; and in small numbers in a further 110 $(35.5 \%)$. The total number of glands showing lesions was $144(41 \cdot 5 \%)$ and those with no lesions $166(58 \cdot 5 \%)$.

The cases were divided into age groups (Fig. 1). The first group (a) comprised stillborn infants and those dying during the first week after birth. (It was thought unjustified to subdivide this age period.) The other cases were divided into groups of approximately the same number: (b) 29 cases aged 1 to 4 weeks; (c) 41, aged 1 to 3 months; (d) 25 , aged 3 months to 6 months; (e) 32 , aged 6 months to 9 months; $(f) 34$, aged 9 to 18 months; 
(g) 46 , aged 18 months to 3 years; (h) 43, aged 3 years to 8 years; and $(i) 17$, aged over 8 years. When the percentage of organs showing lesions in these groups was compared (Fig. 1) a fairly uniform fall

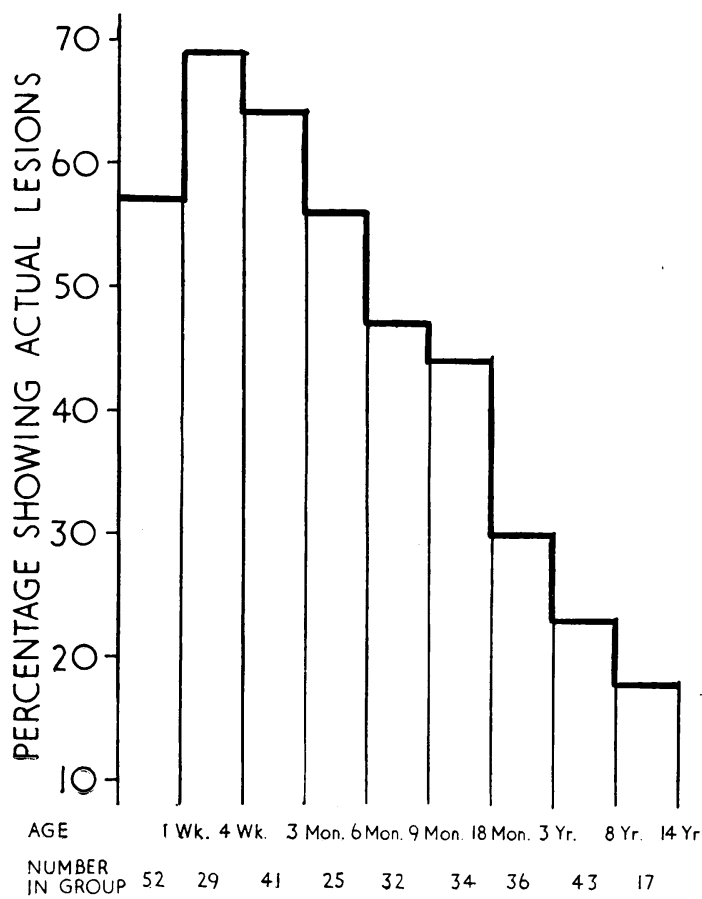

FIG. 1.-Diagram showing the percentage incidence of acinal lesions in different age groups.

in incidence was found: (a) $57 \%$, (b) $69 \%$, (c) $64 \%$, (d) $56 \%$, (e) $47 \%,(f) 44 \%,(g) 30 \%$, and $(i) 18 \%$, giving a statistically significant difference between the first and last two groups.

Classified according to duration of illness the following results were obtained. Of 43 cases dying within the first 24 hours, $17(42 \%)$ showed plugged acini; of 50 cases dying between one and five days, $23(46 \%)$ had lesions; of 37 cases dying between six and 14 days, $17(46 \%)$; of 26 dying between 15 and 32 days, $16(61 \%)$; and in the largest group, 136 , in which the duration of illness was over one month, $64(47 \%)$ lesions were found. It was felt that there was no significant difference between these groups.

Although minor respiratory infections were present in a large number of instances there were 69 cases when this was the primary cause of death. Twenty-two of these were staphylococcal infections, and the remaining 47 were due to other organisms. Fourteen $(63 \%)$ of the staphylococcal group showed plugged acini compared with $23(48 \%)$ of the others.
Sixty-one cases had gross congenital deformities, and $41(67 \%)$ of these had plugged acini. The disease with the lowest number of plugs was tuberculosis with an incidence of $18 \%$ (eight of 44 cases). Other diseases provided too small numbers to give figures useful for comparison.

\section{Discussion}

The finding of plugged acini (Figs. 2 and 3) in $46 \%$ of the children was an unexpectedly high figure, but this was less than the incidence $(52 \%)$ found by Baggenstoss (1948a) in uraemia. Andersen in her original paper examined sections of the pancreas in 605 cases from 1,000 necropsies. She found 20 cases $(3.3 \%)$ in which $90 \%$ or more of the pancreas was involved, 21 cases $(3.5 \%)$ in which $20-30 \%$ was involved, and 69 cases $(11 \cdot 4 \%)$ in

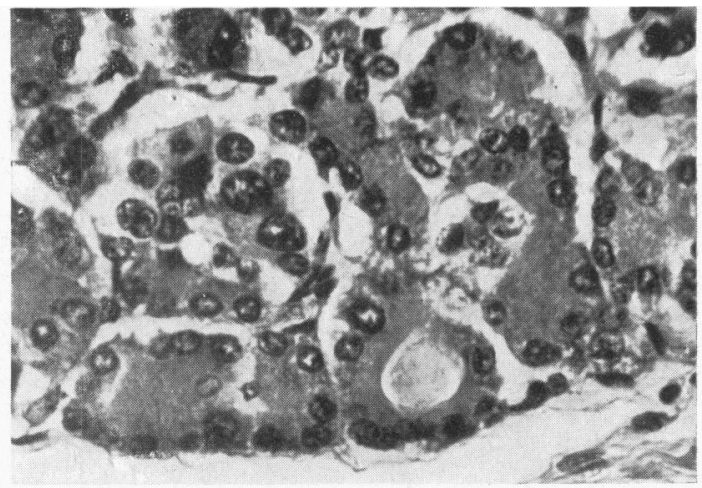

FIG. 2.

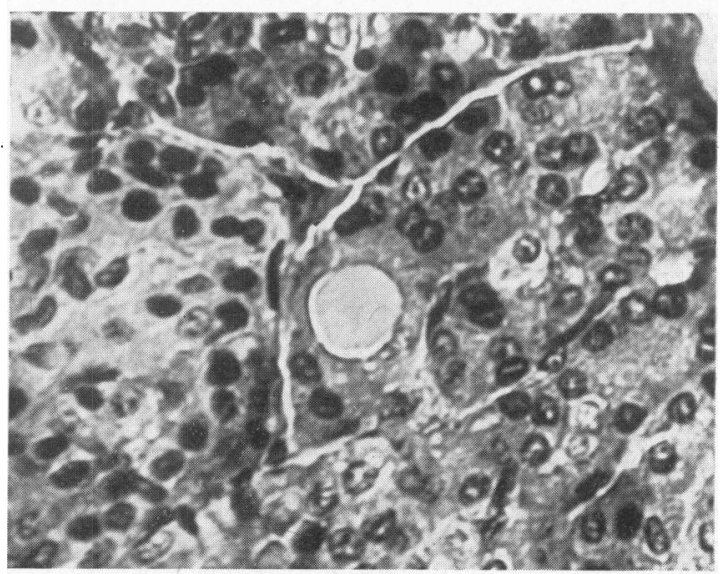

FIG. 3.

FIGS. 2 and 3.-Microphotographs showing isolated cystic acini in otherwise normal pancreatic glands.

Fig. $2 \times 490$. Haematoxylin and eosin.

Fig. $3 \times 590$. Haematoxylin and eosin. 
which smaller numbers of cysts were found. In view of the finding in the present series that the incidence of plugged acini varies greatly with the age of the child, it will be obvious that it is not profitable to compare figures unless they are confined to narrow age groups. If in the present series the children under 18 months are excluded, the incidence of lesions is approximately $30 \%$, which may then be compared with the incidence of $18.2 \%$ in Andersen's series. It would seem that the differences with Andersen's figures could be explained by age and chance, and also by the fact that in the present series a definite search was made for the minimal lesions, whereas Andersen's chief concern was with the gross lesion of the fibrocystic syndrome.

The variation with age (Fig. 1) found in the present study appears to be much greater than could be accounted for by chance. Whether the lesions appear with even greater frequency before birth I am unable to say, as in the five foetal pancreatic glands available to me between the ages of 4 to 8 months lesions were found in only one, but postmortem changes limited critical histological comment. The incidence of lesions in the pancreas seems to parallel the rate of growth of the child. It was shown by Gillman, Gillman, Mandelstam, and Gilbert (1945) and by Kristal (1947) that fibrosis of the liver and pancreatic lesions could be produced much more readily in growing than in mature rats when fed on a diet deficient in protein. It is well known that deficiency states are most liable to occur in growing animals. The incidence (18\%) of acinar plugs in older children is comparable with the $20 \%$ found in adults by Baggenstoss in his control series. It is notable that the incidence of the plugged acini shows a parallel age incidence to fibrocystic disease (Andersen, 1938), and that it is not until later in childhood that the general histological appearance of the pancreas is similar to that in the adult (Emery, 1951).

Andersen found a number of pancreatic glands $(15 \%)$ in which lesions similar to those in fibrocystic disease were present and in which the children showed no symptoms of the latter syndrome. Blackfan and May (1938) found 200 cases with minor asymptomatic lesions in a series containing 35 full lesions. The same occurred in the present series; a large number of glands had minimal lesions (110), a few noticeable lesions (23), all being symptomless, and a small number (11) with the full fibrocystic syndrome. Degrees of the fibrocystic syndrome do occur clinically (Gibbs, Bostick, and Smith, 1950). Farber (1944) considers that these acinal lesions themselves produce the grossly scarred and fibrotic gland. It seems that the fibrocystic disease syndrome may be the end stage of a disorder which is present in a large number of infants and which is progressive in some, as yet, unrecognized circumstances. It is notable that on genetic grounds Lowe, May, and Reed (1949) state that a recessive hereditary factor for fibrocystic disease is present in 2 to $18 \%$ of the general population.

The varied incidence of plugged acini with age was found to interfere greatly with attempts to relate the lesion with particular diseases or incidents. The diseases which showed the lowest incidence of acinar lesions were tuberculous meningitis and miliary tuberculosis, in which lesions were found in only eight $(18 \%)$ of 44 cases, but the average age at death of these cases was 4 years 10 months, which makes the incidence not significantly different from the general incidence $(23 \%)$ for children of this age. Similar difficulties were found when comparing other diseases such as staphylococcal and other infections. It is obvious that very large series of cases of identical age groups would be necessary in order to prove differences in disease incidence.

There appears to be an incidence of plugged pancreatic acini in between 10 and $20 \%$ of general necropsies. Baggenstoss found the lesions in $20 \%$ of 100 controls in his nephritis series and Menten and Kinsey (1949) found cysts in 35 of 256 necropsies not associated with any particular disease or age, and Mallory (1947) in $10 \%$ of post-mortem material in Italy in World War II. If we exclude the finding of cystic areas in association with surgical lesions of the pancreas, e.g. tumours, stones, and congenital deformities, an increased incidence of plugged acini has been reported in association with several apparently diverse conditions. There is an increase in old age both in man and dogs (Wallace and Ashworth, 1942), and in senile rats (Andrew, 1944); in nephritis and renal failure (Baggenstoss, 1947); and Ball, Baggenstoss, and Bargen (1950) found an incidence of $53 \%$ in 91 cases of ulcerative colitis. The lesion occurs in severe wasting disease in the Bantu (Gillman and Gillman, 1945). Mallory (1947) reported that he found lesions in all of a series of 24 necropsies in typhus. All of the above conditions, with the exception of senility, appear to be associated with a severe nutritional upset. Waterlow (1948), however, did not find lesions in the pancreas in children with severe malnutrition in the West Indies, or Davies (1948) in Uganda, but their histological material does not appear to have been good. In growing rats a diet low in protein produces cystic lesions in the pancreas very like the lesion in fibrocystic disease (Kristal, 1947; Véghelyi, Kemény, Pozsonyi, and Sos, 1950). Friedman and Friedman (1946) produced similar lesions in rats with a high fat, low protein diet. 
The only vitamin deficiency which produces lesions in the pancreas is vitamin $\mathrm{A}$, and lesions produced by this means have been described in children (Wilson and DuBois, 1923; Wolbach and Howe, 1925), but the aetiology in these cases is not entirely convincing and Andersen (1949) was unable to produce the lesion in neonatal rats when developed on a diet deficient in vitamin A.

An entirely different approach, that of stimulating the vagus and administrating pancreozymin, has been shown to produce colloidal material in pancreatic acini in cats (Babkin, Rubaschkin, and Ssawitsch, 1909; Sergeyeva, 1938; and others), although this was not confirmed by Harper and Mackay (1948). Ramsay, Thomas, and Crider (1943) produced the same change by administering peptone directly into the duodenum and small bowel. These stimulative effects on the pancreas produce thin, thread-like material in the acini and ducts and a picture similar to that seen in some of the illustrations of normal pancreas in the old German literature (Stangl, 1901). These changes are not similar to the lesions described in this paper but they do indicate a method of production of inspissated secretion.

The conclusion appears to be that lesions of the acini of the pancreas most resembling those in children are associated in man with disorders of the intestinal tract, particularly those associated with wasting and disease where protein metabolism is grossly upset. The observation of Tarver and Schmidt (1942) that the cells most actively handling protein are those of the pancreas and the intestinal mucosa suggest that these cells may be most readily disorganized as a result of protein deficiency.

It is tempting to postulate that the increased incidence of plugged acini found in children in their most active growing period is related to their relatively enhanced nutritional requirements at that time.

\section{Summary}

The pancreas has been examined histologically for the presence of plugged and cystic acini in 310 necropsies at the Children's Hospital, Sheffield.

Cysts were found in $144(46 \cdot 5 \%)$ of the cases; in small numbers in $110(35.5 \%)$ cases, in larger numbers in $23(7.5 \%)$ cases, and in the frank fibrocystic syndrome in $11(3 \cdot 5 \%)$.

It was found that there was a marked variation of incidence with age, the incidence under six months being over $60 \%$ and falling to the adult level of about $20 \%$ by the age of 9 years.

It was found that the varying incidence with age eliminated differences in incidence apparently associated with different diseases.

After considering the experimental and other causes of cystic lesions in the acini of the pancreas it is suggested that the high incidence of cysts in the period of most active growth may be related to the child's enhanced protein requirements at that period.

\section{REFERENCES}

Andersen, D. H. (1938). Amer. J. Dis. Child., 56, 344. (1949). Amer. J. Path., 25, 163.

Andrew, W. (1944). Amer.J. Anat., 74, 97.

Babkin, B. P., Rubaschkin, W. J., and Ssawitsch, W. W. (1909). Arch. mik. Anat., 74, 68.

Baggenstoss, A. H. (1947). Amer. J. Path., 23, 908. (1948a). Ibid., 24, 1003.

(1948b). Arch. Path., Chicago, 45, 463.

Ball, W. P., Baggenstoss, A. H., and Bargen, J. A. (1950). Ibid., 50, 347.

Blackfan, K. D., and May, C. D. (1938). J. Pediat., $13,627$.

Davies, J. N. P. (1948). Lancet, 1, 317.

Emery, J. L. (1951). J. Anat., Lond., 85, 159.

Farber, S. (1944). Arch. Path., Chicago, 37, 238.

Gibbs, G. E., Bostick, W. L., and Smith, P. M. (1950). J. Pediat., 37, 320.

Friedman, S. M., and Friedman, C. L. (1946). Canad. med. Ass. J., 55, 15.

Gillman, T., and Gillman, J. (1945). Arch. Intern. Med., 76, 63.

Gillman, J., Gillman, T., Mandelstam, J., and Gilbert, D. (1945). Brit. J. exp. Path., 26, 67.

Harper, A. A., and Mackay, I. F. S. (1948). J. Physiol. Lond., 107, 89.

Hartz, H. (1948). Ned. Tijdschr. Geneesk., 92, 1217.

Kristal, J. (1947). S. Afr. J. med. Sci., 12, 47.

Lowe, C. U., May, C. D., and Reed, S. C. (1949). Amer. J. Dis. Child., 78, 349.

Mallory, T. B. (1947). Amer. J. Path., 23, 908.

Menten, M. L., and Kinsey, W. C. (1949). Arch. Path., Chicago, 47, 90.

Ramsay, A. J., Thomas, J. E., and Crider, J. O. (1943). Anat. Rec., 86, 87.

Sergeyeva, M. A. (1938). Ibid., 71, 319.

Stangl, E. (1901). Wien. klin. Wschr., 14, 964.

Tarver, H., and Schmidt, C. L. A. (1942). J. Biol. Chem., 146, 69.

Véghelyi, P. V., Kemény, T. T., Pozsonyi, J., and Sos, J. (1950). Amer. J. Dis. Child., 79, 658.

Wallace, S. A., and Ashworth, C. T. (1942). Tex. J. Med., 37, 584.

Waterlow, J. C. (1948). Spec. Rep. Ser. Med. Res. Coun., Lond., No. 263.

Wilson, J. R., and DuBois, R. O. (1923). Amer. J. Dis. Child., 26, 431 .

Wolbach, S. B., and Howe, P. R. (1925). .J. exp. Med., 42, 753 . 